\title{
Pegylated liposomal doxorubicin as first-line monotherapy in elderly women with locally advanced or metastatic breast cancer: Novel treatment predictive factors identified
}

\author{
Henrik Green, Olle Stål, K Bachmeier, L M Bäcklund, L Carlsson, J Hansen, \\ M Lagerlund, B Norberg, A Franzén, A Åleskog and Annika Malmström
}

\section{Linköping University Post Print}

N.B.: When citing this work, cite the original article.

Original Publication:

Henrik Green, Olle Stål, K Bachmeier, L M Bäcklund, L Carlsson, J Hansen, M Lagerlund, B Norberg, A Franzén, A Åleskog and Annika Malmström, Pegylated liposomal doxorubicin as first-line monotherapy in elderly women with locally advanced or metastatic breast cancer: Novel treatment predictive factors identified, 2011, Cancer Letters, (313), 2, 145-153. http://dx.doi.org/10.1016/j.canlet.2011.07.017

Copyright: Elsevier http://www.elsevier.com/

Postprint available at: Linköping University Electronic Press http://urn.kb.se/resolve?urn=urn:nbn:se:liu:diva-73049 
Article Type: Original article

Pegylated liposomal doxorubicin as first-line monotherapy in elderly women with locally advanced or metastatic breast cancer: novel treatment predictive factors identified

H Green ${ }^{1}$, O Stål ${ }^{2}$, K Bachmeier ${ }^{3}$, LM Bäcklund ${ }^{4}$, L Carlsson ${ }^{5}$, J Hansen ${ }^{3}$, M Lagerlund $^{6}$, B Norberg ${ }^{7}$ Å Franzén ${ }^{8}$, A Åleskog ${ }^{8}$, A Malmström ${ }^{9}$

${ }^{1}$ Clinical Pharmacology, Department of Medical and Health Sciences, Linköping University, Linköping, Sweden, and Science for Life Laboratory, Division of Gene Technology, Royal Institute of Technology, Solna, Sweden; ${ }^{2}$ Division of Oncology, Department of Clinical and Experimental Medicine, Faculty of Health Sciences, Linköping University, Linköping, Sweden; ${ }^{3}$ Department of Oncology, Central Hospital, Karlstad, Sweden; ${ }^{4}$ Karolinska Institutet, Department Oncology-Pathology, Karolinska University Hospital, Stockholm, Sweden; ${ }^{5}$ Department of Oncology, District Hospital, Sundsvall, Sweden; ${ }^{6}$ Department of Surgery, District Hospital, Kalmar, Sweden;

${ }^{7}$ Department of Oncology, Ryhov District Hospital, Jönköping, Sweden; ${ }^{8}$ MSD Sweden, Stockholm, Sweden; ${ }^{9}$ Department of Clinical and Experimental Medicine, Faculty of Health Sciences, Linköping University, Unit of Advanced Palliative Homecare, County Council of Östergötland, Linköping, Sweden.

${ }^{*}$ Schering-Plough, Sweden, Stockholm, Sweden, at the time of the study

Corresponding author:

Dr Annika Malmström

Unit of Advanced Palliative Home Care

University Hospital

58185 Linköping

Sweden

Telephone: +46101030000

Fax: +46 10-103 4701

Email: annika.malmstrom@lio.se 


\section{$\underline{\text { Abstract }}$}

We investigated the efficacy and safety of single-agent pegylated liposomal doxorubicin

(PLD) as first-line treatment for elderly women with advanced breast cancer and evaluated predictive markers for response and toxicity.

25 women $\geq 65$ years received $40 \mathrm{mg} / \mathrm{m}^{2}$ PLD every 28 days. Time to treatment failure (TTF), response rate, time to progression (TTP), overall survival (OS), and analysis of the $A B C B 1$ single nucleotide polymorphism (SNP), the MRN complex, and TOPOIla were analyzed. A mean of 7.4 cycles PLD were administered and TTF was 5.5 months and OS 20.6 months.

$A B C B 1$ SNPs were found to correlate to both efficacy and toxicity, while tumor expression of the MRN complex and TOPOlla correlated to TTP.

PLD is a safe and effective treatment for elderly breast cancer patients. Also potential predictive markers were identified.

\section{Key words:}

Anthracycline, elderly, genotype, metastatic breast cancer, MRN complex, topoisomerase Ila

\section{Introduction}

A common clinical dilemma regarding elderly women with advanced breast cancer is the choice of chemotherapy, as approximately $50 \%$ of diagnoses occur after age 65 and few clinical trials have studied aged patients [1-4]. Treatment of elderly can 
be challenging due to comorbidity, risk of toxicity, and reduced quality of life. For these reasons, single-agent therapy is generally advocated [5,6]. Evaluating different chemotherapy regimens for elderly women with breast cancer should include investigating factors that could facilitate selection of patients with the best chance of treatment benefit. Efficacy and toxicity are influenced by both host and tumor factors, which may include the expression of P-glycoprotein (encoded by the ABCB1 gene) and DNA repair proteins [7].

Anthracyclines are among the most active agents for the treatment of breast cancer, but are limited by toxicities including myelosuppression, mucositis, nausea and vomiting, and of special concern in the elderly, cardiotoxicity [2,8]. Pegylated liposomal doxorubicin (PLD) is a liposomal encapsulated form of doxorubicin with a longer halflife, higher tumor tissue penetration, and reduced toxicity [9]. A large phase III study demonstrated PLD to have similar efficacy, improved cardiac safety, and a lower incidence of alopecia, nausea, vomiting, and myelosuppression compared with conventional doxorubicin as first-line treatment of metastatic breast cancer (MBC) [9]. However, PLD was associated with a higher incidence of palmar-plantar erythrodysesthesia (PPE) and mucositis. A reduction of PLD from standard dose 50 $\mathrm{mg} / \mathrm{m}^{2}$ to $40 \mathrm{mg} / \mathrm{m}^{2}$ resulted in comparable efficacy, but reduced incidence of PPE in a prospective phase II trial $[8,18]$.

The aim of this study was to investigate the efficacy and safety of single-agent PLD $40 \mathrm{mg} / \mathrm{m}^{2}$ as first-line treatment for elderly women with breast cancer, either locally-advanced or metastatic, and to search for predictive markers for treatment response and toxicity. These included single nucleotide polymorphisms (SNPs) of the 
$A B C B 1$ gene and tumor tissue investigations for the drug-related target topoisomerase Ila (TOPOIla) and the MRE11/RAD50/NSB1 (MRN) complex involved in DNA repair [10].

\section{Materials and Methods}

\subsection{Eligibility Criteria}

Eligible patients included women $\geq 65$ years with inoperable, locally advanced, or metastatic breast cancer with measurable or non-measurable disease. Patients had to demonstrate WHO performance status $0-2$, a left ventricular ejection fraction (LVEF) $\geq$ $50 \%$ with no clinical signs of heart disease, and normal organ function (except for patients with liver metastases, ALT and/or AST $\leq 5$ times the upper normal limit was accepted). Adequate bone marrow function defined as platelets $\geq 100 \times 10^{9} / \mathrm{L}$, neutrophils $\geq 1.5 \times 10^{9} / \mathrm{L}$, white blood cells $(\mathrm{WBC}) \geq 3.0 \times 10^{9} / \mathrm{L}$, and a hemoglobin $>90 \mathrm{~g} / \mathrm{L}$ was required as was a life expectancy of $\geq 12$ weeks. All patients received oral and written information, and provided written informed consent.

Major exclusion criteria included previous chemotherapy for MBC, recurrence $<12$ months after adjuvant anthracycline, myocardial infarction within 6 months of planned inclusion, and symptomatic brain metastasis. Patients eligible for trastuzumab or endocrine therapy were excluded.

The study was approved by the Ethics Committee at the University Hospital in Linköping, Sweden (M172-06), and the trial was registered at www.clinical trials.gov (NCT 0060 4968). 


\subsection{Study Design}

This was a multicenter, open, single-arm, phase IV study. Patients received PLD $40 \mathrm{mg} / \mathrm{m}^{2}$ intravenously every four weeks. Dose modifications were permitted for hematologic and non-hematologic toxicity. Treatment was continued until progression, unacceptable toxicity, or by physician or patient decision to withdraw from the study. Efficacy and safety were assessed.

\subsection{Study Objectives}

The primary endpoint of the study was time to treatment failure (TTF). Treatment failure was defined as progression of disease or unacceptable toxicity leading to discontinuation of treatment or death. Secondary endpoints were safety, response rate, time to progression (TTP), overall survival (OS), and analysis of potential treatment predictive factors, including SNPs of the ABCB1 gene and analyses of tumor tissue.

\subsection{Efficacy Measurements}

For all patients TTF, OS, number of patients requiring dose reduction, and total number of cycles received were calculated. For patients with measurable disease TTP and response rate (complete response $[\mathrm{CR}]$, partial response $[\mathrm{PR}]$, stable disease $[\mathrm{SD}]$, and progressive disease [PD]) was determined according to RECIST criteria except in patients with bone metastasis where WHO criteria were used [11,12]. Both RECIST and WHO criteria were used for patients with measurable disease and bone metastases.

Tumor evaluation was performed by radiology and physical examination at baseline and every 12 weeks after the start of treatment. Radiological procedures 
included a computerized tomography (CT) or ultrasound of the abdomen, CT or x-ray of the thorax, bone scan and x-ray of hot spots.

\subsection{Safety Measurements}

All adverse events (AEs) were graded according to NCI Common Terminology Criteria for Adverse Events (CTCAE) version 3.0 [13]. Serious AEs (SAEs) were defined as any adverse drug or biologic experience occurring at any dose resulting in death, lifethreatening AEs, persistent or significant disability/incapacity, or in-patient hospitalization.

Cardiac monitoring was by ultrasonic echocardiography (UCG) with calculation of LVEF, and was performed every 12 weeks for patients having previously received anthracyclines and every 6 months for anthracycline-naïve patients. Once patients received 12 cycles of PLD, UCG was performed every 12 weeks unless the cumulative dose of doxorubicin exceeded $550 \mathrm{mg} / \mathrm{m}^{2}$, where UCG was performed every 8 weeks.

\subsection{Tumor Markers Including TOPOIla and the MRN Complex}

Information was collected on the primary tumor and metastases for estrogen and progesterone receptors, HER2 status and tumor grade. Ki67 was assessed with the mouse monoclonal antibody MiB-1 m7240 (Dako, Carpenteria, CA, USA). Expression of MRE11, RAD50, and NSB1 proteins (forming the MRN complex) and TOPOIla in the primary tumor was determined using immunohistochemistry. 
Sections of 4-5 $\mu \mathrm{m}$, cut from paraffin-embedded, formalin-fixed tumor tissue, were deparaffinized and rehydrated. Antigen retrieval was performed by heating in 10\% Diva solution (Dako, Carpenteria, CA, USA) in a decloaking chamber (Digital decloaking chamber DC2002, Biocare medical, Concord, CA, USA). The settings were $125^{\circ} \mathrm{C}$ for 30 seconds and $90^{\circ} \mathrm{C}$ for 10 seconds. Slides were then cooled down to room temperature for 20 minutes. Serum-free protein block (Dako) was used for all antibodies and phosphate buffered saline/ $0.1 \%$ bovine serum albumin was used for washing and antibody dilution. The MRE11 (Clone 12D7) and RAD50 (13B3/2C6) antibodies (Abcam, Cambridge, UK) were used at 1:200 dilution for 1 hour at room temperature and at 1:400 dilution overnight at $4^{\circ} \mathrm{C}$, respectively. The p95/NBS1 antibody (Cell Signaling Technology, Beverly, MA, USA) was used at 1:100 dilution for 2 hours at room temperature, and the TOPOIla (clone Ki-S1) antibody (Dako) was used at 1:100 dilution overnight at $4^{\circ} \mathrm{C}$. DAKO EnVision+ was used as secondary antibody for 30 minutes at room temperature. The immunostaining was visualized using 3, 3'diaminobenzidine and hydrogen peroxide for 8 minutes. After washing, the slides were counterstained with hematoxylin, dehydrated, and mounted.

\subsection{Evaluation of Immunostaining}

The immunohistochemical staining was evaluated independently by two investigators blinded to clinical data. In cases of discrepant scoring, a consensus score was reached after re-evaluation. For the MRN proteins, a proportion score, representing the estimated proportion of stained cell nuclei $(0=$ no stained cell nuclei; $1=1-25 \%$; $2=26-50 \% ; 3=51-75 \% ; 4=76-100 \%$ ) and an intensity score, representing the intensity of the stained cell nuclei $(0=$ no staining; $1=$ weak staining; $2=$ moderate staining; 
3=strong staining) was assigned. For TOPOlla, the proportion score was slightly different $(0=<10 \% ; 1=11-25 \% ; 2=26-50 \% ; 3=51-75 \% ; 4=76-100 \%)$. The proportion and intensity scores were then added to obtain a total score, ranging from 0-7.

\subsection{Genotyping of ABCB1}

Genomic DNA was isolated from whole blood using the Maxwell 16 blood DNA purification kit from Promega (Madison, WI, USA). The genotypes for the ABCB1 SNPS G1199A, C1236T, G2677T/A, and C3435T were determined using pyrosequencing as previously described [14,15]. In short, a HotStarTaq master mixture (VWR International, Stockholm, Sweden) was used for PCR amplification, and all reactions were carried out on a Mastercycler gradient instrument (Eppendorf, Germany) in a total volume of $25 \mu \mathrm{L}$. The SNPs were analyzed using a Pyrosequencing PSQ96MA instrument (Qiagen, Stockholm, Sweden) according to the manufacturer's protocol by annealing a specific sequencing primer to a single stranded PCR-product and dispensing single nucleotides in a predesigned order [14,15].

\subsection{Statistical Methods}

The primary endpoint, median TTF, was assumed to be 7 months. A sample size of 25 patients was expected to produce a 95\% confidence interval $(\mathrm{Cl})$ of 3.6-12 months. TTF was measured from date of first treatment to date of event and censored for patients with no event at the date of last visit. TTF, TTP, and OS were calculated by using the Kaplan-Meier estimate and log-rank test when comparing subgroups of patients. 
Response and progression were defined as the first evaluation that showed response or progression, respectively. Response had to be confirmed by two observations not less than 4 weeks apart. Duration of response was defined as the time span between first response and first progression.

\section{Results}

3.1 Patient Demographics

Twenty-five patients were enrolled at five centers in Sweden from February 2007 to October 2008. Median patient age was 72 years (See table 1 for Patient and Tumor Characteristics).

\subsection{Efficacy}

Median TTF was 5.5 months (CI 95\%: 3.67, 8.52), median TTP was 5.7 months (CI 95\%: 3.74, 13.8), and median OS was 20.6 months (CI 95\%: 6.58, 25.6). Of the 25 enrolled patients, three had non-measurable disease and were not included in the response analysis. They were withdrawn from the study without documented progression after 6,7 , and 11 cycles, respectively. Eighteen patients were assessed by RECIST or a combination of RECIST and WHO criteria, and four by WHO criteria only. Of these, three achieved a PR, and 13 had SD; six had PD as best response. Six of the 16 patients with SD or non-measurable disease received $\geq 7$ cycles of therapy, resulting in 6 months or longer disease stabilization.

\subsection{Safety}


Patients received a median of 6 cycles and mean of 7.4 cycles (range 1-21 cycles) of therapy. The majority of AEs were mild to moderate in severity and transient; no grade 3-4 hematologic toxicities were noted. The main related toxicities (all grades) were nausea (60\%), fatigue (56\%), and PPE (52\%) (Table 2 - grade 3 and 4 toxicity). Four SAEs were reported possibly related to PLD.

Clinically significant cardiac events were noted in three patients: one grade 2 heart valve dysfunction and grade 1 left ventricular dysfunction; one grade 4 myocardial infarction and heart failure; and one grade 2 tachycardia, the latter two leading to PLD discontinuation. Four decreases in LVEF did not meet criteria for study withdrawal.

Study drug was also discontinued in two patients due to severe PPE. PLD dose was reduced in 10 patients, six due to weight loss and four due to: PPE(2), rash(1), and diarrhea(1).

\subsection{Single Nucleotide Polymorphism in ABCB1 Gene}

Twenty-four patients were genotyped for the ABCB1 SNPs (Table 3). One patient with a G/A genotype of G2677T/A was excluded from further analysis. For the variant G1199A, only 1 patient had the G/A genotype, and this SNP was not evaluated for clinical response. TTF by ABCB1 genotypes G2677T and C3435T are shown in Figure 1, and the genotype effects on TTP are shown in Figure 2. The mean TTF and mean TTP for the ABCB1 genotypes are presented in Table 3. The estimated mean TTF and TTP were significantly longer for patients who were wild type for G2677T, intermediate for heterozygous, and shortest for homozygous variant patients. A similar, but nonsignificant trend was seen for the ABCB1 SNP C3435T. Patients with the 3435T/T 
genotype were significantly more susceptible to moderate to severe PPE $(P=0.02)$, where 5 of the $8 \mathrm{~T} / \mathrm{T}$-patients suffered moderate to severe PPE, while this was true for only 2 of 16 patients with non-3435T/T genotype (Figure 3). No correlation between myelosuppression or cardiotoxicity and ABCB1 genotype was demonstrated.

\subsection{Investigations of Primary Tumor Tissue}

No significant association of grade, estrogen or progesterone receptor and HER2 status, with TTF or TTP was found. For seven patients with triple-negative tumors TTF and TTP were similar to those in the other subgroups. Patients with tumors with low proliferation rate (Ki67 $\leq 10 \%)$ had significantly longer TTF $(P=0.00051)$ and TTP $(P=0.0062)$ than those with intermediate or highly proliferative tumors (Figure 4A). (See table 1 for Patient and Tumor characteristics) Patients with a high intensity score for tumoral TOPOlla showed non-significant trends of longer TTF $(P=0.19)$ and TTP $(P=0.20)$. The TOPOlla score correlated with Ki67 $(P=0.044)$. To adjust for this association, a ratio between the TOPOlla intensity and Ki67 scores was established and patients were categorized into two groups with a low ratio $(n=10)$ and a high ratio $(n=10)$, respectively. Patients with a high ratio showed significantly longer TTF $(P=0.0028)$ and TTP $(P=0.0043)$ than patients with a low ratio (Figure 4B).

The immunoscores for the individual proteins in the MRN complex were not significantly associated with TTF or TTP, although a low score $(<6)$ for RAD50 $(P=0.096)$ as well as a low score for MRE11 $(P=0.20)$ was weakly associated with longer TTP. An MRN scoring system was created such that a low score was defined by all three proteins individually having low scores $(<6)$. None of the six patients with a low 
MRN score showed progression during the time of follow-up (Figure 4C). Figure 4D-F show examples of the immunostaining for Ki67, TOPOlla and MRE11

The findings regarding the MRN score and TOPOlla were largely independent of other prognostic tumor characteristics, such as grade and hormone receptor status (data not shown).

\section{Discussion}

The optimal treatment for women over 65 years with locally advanced or MBC has not yet been determined. Exploring the role of different chemotherapeutic agents in this setting via clinical trials is necessary for evidence-based treatment recommendations. Identifying predictive markers for chemotherapy is becoming increasingly important to optimize treatment efficacy and diminish patient suffering due to toxicity.

We conducted a phase IV trial in 25 women with locally advanced or MBC, not amenable to curative treatment, investigating the efficacy and safety of PLD in the firstline setting at a dose of $40 \mathrm{mg} / \mathrm{m}^{2}$ every 28 days until treatment failure. We explored the role of TOPOlla expression and the MRN complex in tumor tissue and different SNPs of the ABCB1 gene in relation to efficacy and treatment toxicity. Despite the small size of this trial, we found clinically interesting correlations.

O'Brien et al compared PLD $50 \mathrm{mg} / \mathrm{m}^{2}$ every 4 weeks with doxorubicin $60 \mathrm{mg} / \mathrm{m}^{2}$ every 3 weeks as first-line treatment for MBC [9]. Median age was 58 years (range 2582 ), with $28 \%$ being $\geq 65$ years. Efficacy was similar between treatment arms, with significantly less cardiac events in the PLD arm. Response rate for PLD was 33\%, and OS was 21 months. PPE grade $3 / 4$ was noted in $17 \%$ and stomatitis in $9 \%$ of patients. 
Similarly, the EORTC reported a retrospective joint analysis of two trials (including data from the study of Coleman) utilizing two different dosing schedules of PLD conducted mostly in patients $>65$ years $[16,17]$. PLD schedules were $50 \mathrm{mg} / \mathrm{m}^{2}$ every 4 weeks or $60 \mathrm{mg} / \mathrm{m}^{2}$ every 6 weeks. Tolerability and efficacy in patients $<70$ years versus $\geq 70$ years were compared, with equivalent efficacy demonstrated (ORRs of approximately $30 \%)$. Toxicity was higher in the older cohort for the six-week schedule, but also noted in the four-week schedule were more treatment discontinuations for toxicity (mainly skin) among elderly patients versus younger patients (29\% vs $14 \%$, respectively). AlBatran et al $(8,18)$ studied response and toxicity of PLD in two different cohorts of pretreated breast cancer patients, the first group receiving $50 \mathrm{mg} / \mathrm{m}^{2}$ and the second 40 $\mathrm{mg} / \mathrm{m}^{2}$. For both studies ORR was $13 \%$, while PPE grade $3 / 4$ was reduced from 6 to $0 \%$ and stomatitis grade $3 / 4$ from 10 to $4 \%$ by decreasing the dose.

In our study, 3 of 22 patients with measurable disease (14\%) had a PR, no patients had a CR, and 13 of 22 patients (60\%) achieved SD. Only 4 patients (16\%) discontinued treatment because of PLD-related AEs: 2 with severe PPE and 2 with cardiac events. Toxicity data compare favorably to the Coleman and O'Brien results of $50 \mathrm{mg} / \mathrm{m}^{2}$ PLD although PPE was more frequent than among the mainly younger patients in the $40 \mathrm{mg} / \mathrm{m}^{2}$ PLD study of Al-Batran. $(8,9,16,17,18)$.

Despite few objective responses, OS of 20.6 months was comparable to that observed in the O'Brien study. TTP was 5.7 months, which is also similar to the other first line studies (range 5.4-6.9 months) using higher dosing (Table 4).

The use of single-agent chemotherapy in our study facilitated identifying important biomarkers that may correlate to outcome or AEs. In the ABCB1 genotype analysis, the 
G2677T genotype had a significant impact on TTF and TTP and C3435T had a nonsignificant trend on TTF and TTP (Figures 1 and 2). TTF and TTP were longest for patients with the wild-type genotype, intermediate for those being heterozygous, and shortest for homozygous variant patients. The G2677T genetic variation results in an amino-acid change from an alanine residue to a serine in P-glycoprotein at position 893, while the C3435T SNP is silent. Due to the fact that the G2677T and C3435T SNPs are linked, our findings corroborate results from Cizmarikova et al [19] who found that patients with the 3435C/C genotype had a longer TTP and an enhanced therapeutic outcome after neoadjuvant anthracycline-based chemotherapy. In accordance, Turgut et al [20] showed a trend toward a shorter PFS for breast cancer patients with 3435T/T compared to heterozygous and wild-type patients. They found no correlation between ABCB1 genotype and response, as also demonstrated by Rodrigues et al [21].

Patients with the ABCB1 C3435T/T genotype were significantly more susceptible to moderate to severe PPE affecting $62 \%$ of patients compared to $12 \%$ of those with non-3435T/T genotype (Figure 3). PPE is believed to be due to PLD excretion through the skin; therefore, an enhanced efflux might promote this toxicity [22]. No correlation between myelosuppression or cardiotoxicity and ABCB1 was demonstrated.

Retrospective studies have shown that amplification of the gene encoding TOPOlla (TOP2A) predicts sensitivity to anthracyclins [23-25]. As TOP2A amplification is almost exclusively found in tumors with HER2 amplification, and a positive HER2 status was an exclusion criterion in our study, we could not justify performing TOP2A analysis with FISH. However, sensitivity to anthracycline-based therapy has also been 
related to high TOP2A expression levels and we hypothesized that high TOPOlla levels, also in the absence of gene amplification, might be predictive [26].

Immunohistochemical staining of TOPOIla likely reflects abnormal expression of the protein, DNA replication, or both, and a positive correlation between TOPOIla and Ki67 was observed. Accordingly, the TOPOIla:Ki67 ratio more accurately predicted TTP than TOPOlla alone.

The MRN complex is an active component in DNA double-strand break repair and may therefore play a role in chemotherapy effect. For cancer cells to resist treatment with drugs that fix topoisomerases to DNA, the topoisomerase must be released. Interestingly, MRN has been shown to be involved in topoisomerase removal, suggesting that impaired MRN function may increase the half lives of DNAtopoisomerase complexes, leading to higher treatment efficiency $[27,28]$. This might be a mechanistic explanation of our finding that patients with reduced MRN expression were less likely to progress.

In summary, our study demonstrated that PLD $40 \mathrm{mg} / \mathrm{m}^{2}$ is a safe and effective treatment for elderly women with breast cancer. We found that SNPs of the ABCB1 gene correlate to both TTF and TTP and the risk of PPE, thereby indicating that the ABCB1 genotype could be a predictive factor for therapy with PLD in these patients. We also showed that expression of TOPOIla and the MRN complex influenced treatment outcome.

Additional investigations of the SNPs of ABCB1, gene expression of TOPOIla and the MRN complex in different age groups receiving PLD or other anthracyclines will help to further define their role for individualized treatment recommendations. 
Funding Source

This study was funded by MSD, formerly Schering Plough Corp. Part of the translational research was also supported by the Swedish Cancer Society and the Swedish Research Council

\section{Acknowledgements}

We would like to acknowledge the women who participated in this study as well as the investigators and their staff, and Phillips Gilmore for technical assistance in preparation of the manuscript.

Conflict of Interest Statement

The following authors of this paper declare that there is no conflict of interest involved in this paper: HG, OS, KB, ML, LC, JH, BN, AM. The following authors declare a conflict of interest: At the time of the study LMB was Project Physician for the study while being employed by Schering-Plough as a Medical Affairs Manager. ÅF previously held a position as Clinical Project Manager at Schering-Plough Sweden and now holds the same position at MSD Sweden. AA currently holds a position as Medical Affairs Manager (Medical Advisor) in oncology at MSD Sweden. 


\section{$\underline{\text { 6. References }}$}

[1] M.J. Horner, L.A.G. Ries, M. Krapcho, et al (2010) SEER Cancer Statistics Review 1975-2006. Bethesda, MD: National Cancer Institute

[2] M. Aapro, C. Bernard-Marty, E.G. Brain, et al, Anthracycline cardiotoxicity in the elderly cancer patient: a SIOG expert position paper. Ann Oncol. Published 18 October 2010. doi:10.1093/annonc/mdq609

[3] M. Debled, N. Nadranges, C. Mertens, et al, First-line chemotherapy for metastatic breast cancer in patients $\geq 75$ years: A retrospective single-centre analysis [published ahead of print 28 October 2010], Crit Rev Hematol Oncol. (2010) doi:10.1016/j.critrevonc.2010.10.002.

[4] The national Board of Health and Welfare Cancer database (2011) Cancer incidence in Sweden 2009. Socialstyrelsen Web site. http://www.socialstyrelsen.se/. Accessed 10 January 2011

[5] D. Crivellari, M. Aapro, R. Leonard, et al. Breast cancer in the elderly, J. Clin Oncol 25 (2007) 1882-1890

[6] H. Wildiers, I. Kunkler, L. Biganzoli, et al, Management of breast cancer in elderly individuals: recommendations of the International Society of Geriatric Oncology. Lancet Oncol 8 (2007) 1101-1115

[7] M. Eichelbaum, M. Ingelman-Sundberg, W.E. Evans, Pharmacogenomics and individualized drug therapy, Annu Rev Med. 57 (2006) 119-37 
[8] S.E. Al-Batran, H.G. Meerpohl, von Minckwitz, et al, Reduced incidence of severe palmar-plantar erythrodysesthesia and mucositis in a prospective multicenter phase II trial with pegylated liposomal doxorubicin at $40 \mathrm{mg} / \mathrm{m}^{2}$ every 4 weeks in previously treated patients with metastatic breast cancer, Oncology. 70 (2006) 141-146

[9] M.E.R. O'Brien, N. Wigler, M. Inbar, et al, Reduced cardiotoxicity and comparable efficacy in a phase III trial of pegylated liposomal doxorubicin $\mathrm{HCl}$ (CAELYX/Doxil) versus conventional doxorubicin for first-line treatment of metastatic breast cancer, Ann Oncol. 15 (2004) 440-449

[10] J.H. Lee, T.T Paull, ATM activation by DNA double-strand breaks through the Mre11-Rad50-Nbs1 complex, Science. 308 (2005) 551-554

[11] P. Therasse, S.G. Arbuck, E.A. Eisenhauer, et al, New guidelines to evaluate the response to treatment in solid tumors. European Organization for Research and Treatment of Cancer, National Cancer Institute of the United States, National Cancer Institute of Canada, J Natl Cancer Inst. 92 (2000) 205-216

[12] Miller et al, Reporting Results of Cancer Treatment, Cancer. 47 (1981) 201-14

[13] Common Terminology Criteria for Adverse Events, version 3.0. Bethesda MD: National Cancer Institute. Published 9 August 2006

[14] H. Gréen, P. Söderkvist, P. Rosenberg, et al, mdr-1 single nucleotide polymorphisms in ovarian cancer tissue: G2677T/A correlates with response to paclitaxel chemotherapy, Clin Cancer Res. 12 (2006) 854-859 
[15] H. Gréen, P. Söderkvist, P. Rosenberg, et al, ABCB1 G1199A polymorphism and ovarian cancer response to paclitaxel, J Pharm Sci. 97 (2008) 2045-2048

[16] L. Biganzoli, R. Coleman, A. Minisini, et al, A joined analysis of two European Organization for the Research and Treatment of Cancer (EORTC) studies to evaluate the role of pegylated liposomal doxorubicin (Caelyx) in the treatment of elderly patients with metastatic breast cancer, Crit Rev Oncol Hematol. 61 (2007) 848-849

[17] R.E. Coleman, L. Biganzoli, P. Canney, et al, A randomized phase II study of two different schedules of pegylated liposomal doxorubicin in metastatic breast cancer (EORTC-10993). Eur J Cancer 42 (2006) 882-887

[18] S.E. Al-Batran, J. Bischoff, G. von Minckwitz, et al, The clinical benefit of pegylated liposomal doxorubicin in patients with metastatic breast cancer previously treated with conventional anthracyclines: a multicentre phase II trial $\mathrm{Br}$ J Cancer 94 (2006) 1615-1620

[19] M. Cizmarikova, M. Wagnerova, L. Schonova, et al, MDR1 (C3435T) polymorphism: relation to the risk of breast cancer and therapeutic outcome, Pharmacogenomics J. 10 (2010) 62-9

[20] S. Turgut, A. Yaren, R. Kursunluoglu, et al, MDR1 C3435T polymorphism in patients with breast cancer, Arch Med Res. 38 (2007) 539-44 
[21] F.F. Rodrigues, R.E. Santos, M.B. Melo, et al, Correlation of polymorphism C3435T of the MDR-1 gene and the response of primary chemotherapy in women with locally advanced breast cancer, Genet Mol Res. 7 (2008) 177-183

[22] A. Martschick, J. Sehouli, A. Patzelt, et al, The pathogenic mechanism of anthracycline-induced palmar-plantar erythrodysesthesia, Anticancer Res. 29 (2009) 2307-2313

[23] T.A. Jarvinen, M. Tanner, V. Rantanen, et al, Amplification and deletion of topoisomerase Ila associate with ErbB-2 amplification and effect sensitivity to topoisomerase II inhibitor doxorubicin in breast cancer, Am J Pathol. 156 (2000) 839-847

[24] A.S. Knoop, H. Knudsen, E. Balslev, et al, Retrospective analysis of topoisomerase lla amplifications and deletions as predictive markers in primary breast cancer patients randomly assigned to cyclophosphamide, methotrexate, and fluorouracil or cyclophosphamide, epirubicin, and fluorouracil: Danish Breast Cancer Cooperative Group, J Clin Oncol. 23 (2005) 7483-7490

[25] F.P. O'Malley, S. Chia, D. Tu, et al, Topoisomerase II $\alpha$ and responsiveness of breast cancer to adjuvant chemotherapy, J Natl Cancer Inst. 101 (2009) 644-650

[26] J.C. Brase, M. Schmidt, T. Fischbach, et al, ERBB2 and TOP2A in breast cancer: A comprehensive analysis of gene amplification, RNA levels, and protein expression and their influence on prognosis and prediction, Clin Cancer Res. 16 (2010) 2391-2401 
[27] E. Hartsuiker, M.J. Neale, A.M. Carr, Distinct requirements for the Rad32Mre11 nuclease and Ctp1 CtIP in the removal of covalently bound topoisomerase I and II from DNA, Mol Cell. 33 (2009) 117-123

[28] N.K. Hamilton, N. Maizels, MRE11 function in response to topoisomerase poisons is independent of its function in double-strand break repair in Saccharomyces cerevisiae, PloS ONE 5. (2010) e15387 1-8 
Table 1. Patient and Tumor Characteristics

\begin{tabular}{|l|l|}
\hline Patient Characteristics & $\mathrm{N}=25$ \\
\hline Mean age, years (range) & $72.3(65-81)$ \\
\hline WHO PS & $10(40 \%)$ \\
0 & $13(52 \%)$ \\
1 & $2(8 \%)$ \\
2 & $6(24 \%)$ \\
\hline Previous adjuvant anthracycline & $61.3 \%(50-75 \%)$ \\
\hline Mean baseline LVEF (range) & \\
\hline Tumor Characteristics & \\
\hline ER status & $18(72 \%)$ \\
Positive & $7(28 \%)$ \\
Negative & $9(36 \%)$ \\
\hline PR status & $16(64 \%)$ \\
Positive & \\
Negative & $1(4 \%)^{\dagger}$ \\
\hline HER2 status & $24(96 \%)$ \\
Positive & \\
Negative & $18(72 \%)$ \\
\hline Triple-negative & $7(28 \%)$ \\
No & $2(9 \%)$ \\
Yes & $8(35 \%)$ \\
\hline Tumor grade & \\
1 & $13(56 \%)$ \\
2 & $6(30 \%)$ \\
3 & $5(25 \%)$ \\
\hline Ki67 & $9(45 \%)$ \\
\hline$\leq 10 \%$ & \\
$11-20 \%$ & \\
$>20 \%$ & \\
\hline
\end{tabular}

${ }^{\dagger}$ Positive HER2 status was determined for metastatic tumor; HER2 status of primary tumor was not assessed. ${ }^{\ddagger}$ Grading available for 23 patients. 
Table 2. Grade 3-4 Treatment-Related Non-Hematologic Adverse Events

\begin{tabular}{|l|c|c|}
\hline & Grade 3 & Grade 4 \\
\hline Diarrhea & $1(4 \%)$ & 0 \\
\hline Nausea & $1(4 \%)$ & 0 \\
\hline Vomiting & $1(4 \%)$ & 0 \\
\hline Fatigue & $1(4 \%)$ & 0 \\
\hline PPE & $2(8 \%)$ & 0 \\
\hline Rash & $1(4 \%)$ & 0 \\
\hline Infection & $1(4 \%)$ & 0 \\
\hline
\end{tabular}


Table 3. Mean TTF and TTP by Single Nucleotide Polymorphism in ABCB1 Gene

\begin{tabular}{|c|c|c|c|c|c|c|}
\hline \multirow{2}{*}{ SNP genotype } & \multicolumn{3}{|c|}{$\begin{array}{c}\text { Mean TTF } \\
\text { Days (95\% Cl) }\end{array}$} & \multicolumn{3}{|c|}{$\begin{array}{c}\text { Mean TTP } \\
\text { Days }(95 \% \mathrm{Cl})\end{array}$} \\
\hline & C1236T & G2677T & C3435T & C1236T & G2677T & C3435T \\
\hline \multirow{2}{*}{ Wild-type patients } & $n=11$ & $\mathrm{n}=9$ & $n=4$ & $n=11$ & $n=9$ & $\mathrm{n}=4$ \\
\hline & $\begin{array}{c}252 \\
(130-374)\end{array}$ & $\begin{array}{c}270 \\
(140-401)\end{array}$ & $\begin{array}{c}363 \\
(83-634)\end{array}$ & $\begin{array}{c}378 \\
(228-527)\end{array}$ & $\begin{array}{c}414 \\
(264-565)\end{array}$ & $\begin{array}{c}470 \\
(228-712)\end{array}$ \\
\hline \multirow{2}{*}{$\begin{array}{l}\text { Heterozygous } \\
\text { patients }\end{array}$} & $n=10$ & $n=12$ & $\mathrm{n}=12$ & $n=10$ & $\mathrm{n}=12$ & $\mathrm{n}=12$ \\
\hline & $\begin{array}{c}203 \\
(114-291)\end{array}$ & $\begin{array}{c}256 \\
(129-385)\end{array}$ & $\begin{array}{c}235 \\
(137-382)\end{array}$ & $\begin{array}{c}235 \\
(137-334)\end{array}$ & $\begin{array}{c}298 \\
(165-431)\end{array}$ & $\begin{array}{c}301 \\
(185-417)\end{array}$ \\
\hline \multirow{2}{*}{$\begin{array}{l}\text { Homozygous } \\
\text { variant patients }\end{array}$} & $n=3$ & $n=2$ & $n=8$ & $n=3$ & $n=2$ & $n=8$ \\
\hline & $\begin{array}{c}266 \\
(0-614)\end{array}$ & $\begin{array}{c}88 \\
(84-92)\end{array}$ & $\begin{array}{c}143 \\
(84-204)\end{array}$ & $\begin{array}{c}266 \\
(0-550)\end{array}$ & $\begin{array}{c}88 \\
(84-92)\end{array}$ & $\begin{array}{c}180 \\
(105-255)\end{array}$ \\
\hline
\end{tabular}


Table 4. Comparative Trials

\begin{tabular}{|c|c|c|c|c|c|c|c|c|c|c|c|c|}
\hline Study & $\begin{array}{l}\text { Number } \\
\text { of } \\
\text { patients }\end{array}$ & $\begin{array}{c}\text { Line of } \\
\text { treatment } \\
\text { metastatic } \\
\text { disease }\end{array}$ & $\begin{array}{l}\text { Dose } \\
\text { PLD }\end{array}$ & Phase & $\begin{array}{c}\text { Age } \\
\text { median } \\
\text { (range) }\end{array}$ & $\begin{array}{c}\text { OR } \\
(\mathrm{CR}+\mathrm{PR}) \%\end{array}$ & SD \% & $\begin{array}{c}\text { TTP } \\
\text { months }\end{array}$ & $\begin{array}{c}\text { OS } \\
\text { months }\end{array}$ & $\begin{array}{l}\text { Cardiac tox } \\
\% \text { all grades }\end{array}$ & $\begin{array}{c}\text { PPE \% } \\
\text { grade } 3 / 4\end{array}$ & $\begin{array}{c}\text { Stomatitis+ } \\
\text { mucositis } \\
\% \text { grade } 3 / 4\end{array}$ \\
\hline O’Brien [9] & $254^{a}$ & $1^{\text {st }}$ line & $\begin{array}{c}50 \mathrm{mg} / \mathrm{m}^{2} \\
\mathrm{q} 4 \mathrm{w}\end{array}$ & $\| I^{\mathrm{b}}$ & $\begin{array}{c}59 \\
(28-82)\end{array}$ & 33 & 25 & 6.9 & 21 & 5 & 17 & 9 \\
\hline Al-Batran [18] & $79^{c}$ & $\geq 2^{\text {nd }}$ line & $\begin{array}{c}50 \mathrm{mg} / \mathrm{m}^{2} \\
q 4 \mathrm{w}\end{array}$ & II & $\begin{array}{c}58 \\
(35-79)\end{array}$ & 13 & 28 & 3.6 & 12.3 & $0^{d}$ & 6 & 10 \\
\hline Al-Batran [8] & 46 & $2-3^{\text {rd }}$ line & $\begin{array}{c}40 \mathrm{mg} / \mathrm{m}^{2} \\
\mathrm{q} 4 \mathrm{w}\end{array}$ & II & $\begin{array}{c}60 \\
(35-82)\end{array}$ & 13 & 35 & 3.3 & 10.7 & 0 & 0 & 4 \\
\hline \multirow[t]{2}{*}{ Coleman [17] } & 116 & $\begin{array}{c}1^{\text {st }} \text { line } \\
51 / 59 \mathrm{pts}^{\mathrm{e}}\end{array}$ & $\begin{array}{c}50 \mathrm{mg} / \mathrm{m}^{2} \\
\mathrm{q} 4 \mathrm{w}\end{array}$ & II $^{f}$ & $\begin{array}{c}69 \\
(43-85)\end{array}$ & 31 & 33 & 5.4 & $\begin{array}{c}\text { not } \\
\text { stated }\end{array}$ & 2 Grade $3 / 4$ & 16 & 14 \\
\hline & & $\begin{array}{c}1^{\text {st }} \text { line } \\
49 / 57 \text { pts }^{\mathrm{e}}\end{array}$ & $\begin{array}{l}\text { vs } 60 \\
\mathrm{mg} / \mathrm{m}^{2} \\
\mathrm{q} 6 \mathrm{w}\end{array}$ & II $^{f}$ & $\begin{array}{c}69 \\
(37-87)\end{array}$ & 29 & 43 & 5.8 & $\begin{array}{c}\text { not } \\
\text { stated }\end{array}$ & 0 Grade $3 / 4$ & 2 & 35 \\
\hline This study & 25 & $1^{\text {st }}$ line & $\begin{array}{c}40 \mathrm{mg} / \mathrm{m}^{2} \\
\mathrm{q} 4 \mathrm{w}\end{array}$ & II & $\begin{array}{c}72 \\
(65-81)\end{array}$ & 14 & 60 & 5.7 & 20.6 & 12 & 8 & 0 \\
\hline
\end{tabular}

${ }^{a}$ Of the 509 patients in the trial, 254 were randomized to PLD

${ }^{\mathrm{b}}$ Compared to doxorubicin $60 \mathrm{mg} / \mathrm{m}^{2}$ q $3 \mathrm{w}$

${ }^{\mathrm{c} A n t h r a c y c l i n}$ pretreated patients

${ }^{d} 5 \%$ of patients had ECG changes related to disease

${ }^{\mathrm{e}}$ Remaining patients treated $\geq 2^{\text {nd }}$ line

fRandomized phase II study 
Figure 1.

A

Wild Type \& Heterozygous vs Homozygous
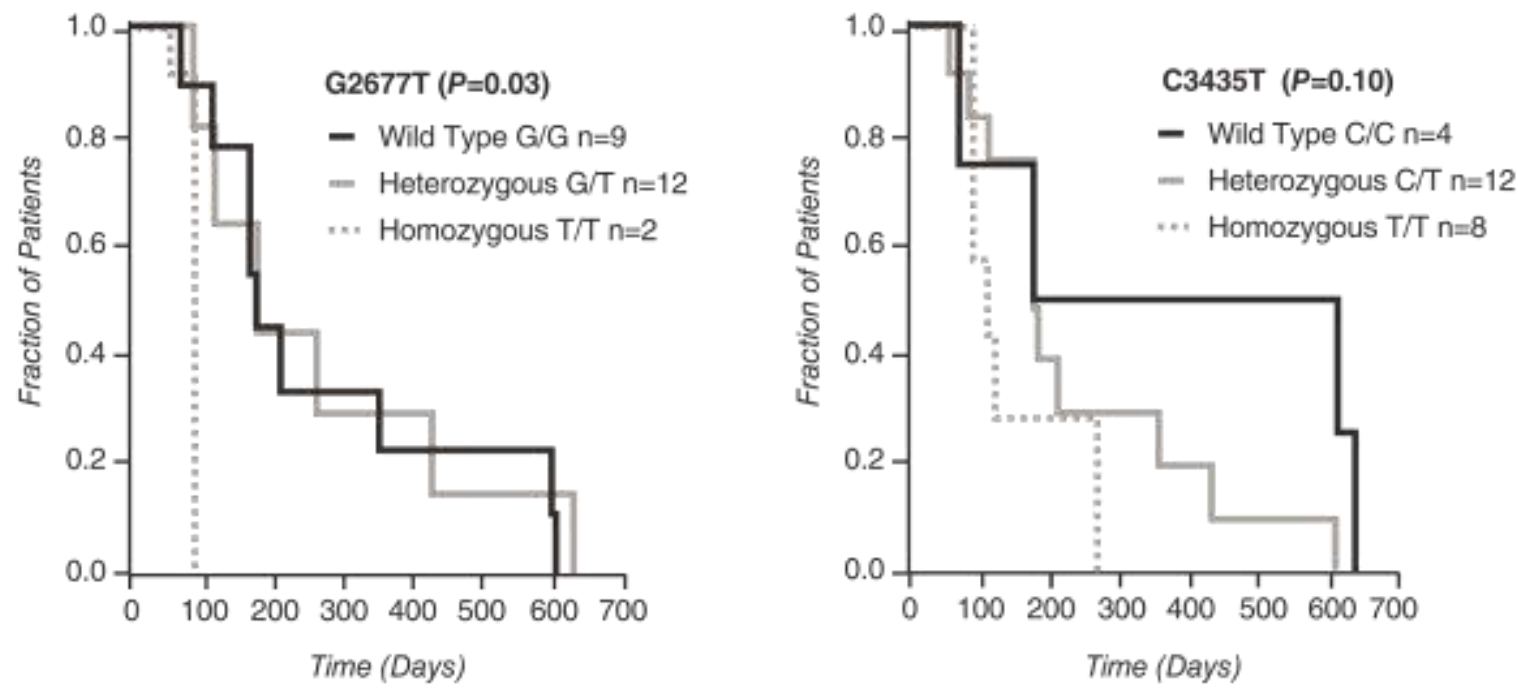

B
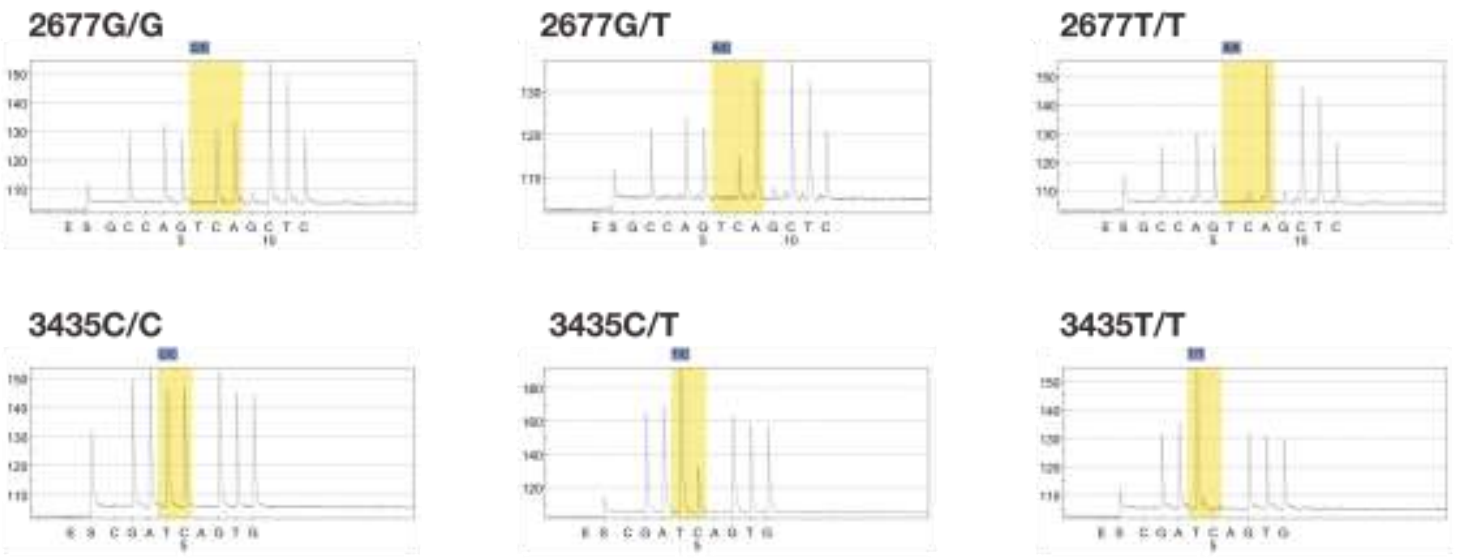
Figure 2.

Wild Type \& Heterozygous vs Homozygous
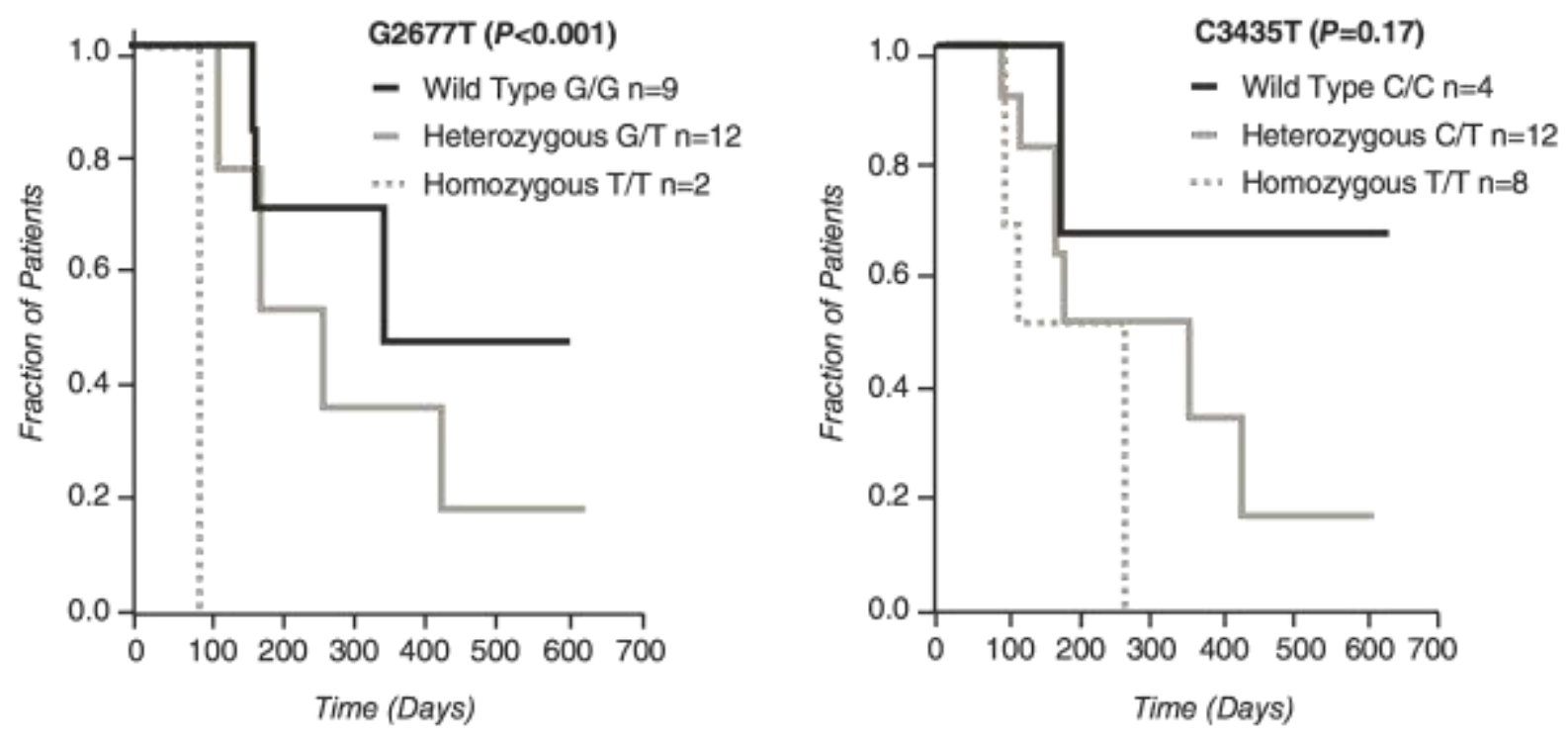
Figure 3.

Skin Toxicity - Severe or Moderate PPE $(P=0.02)$

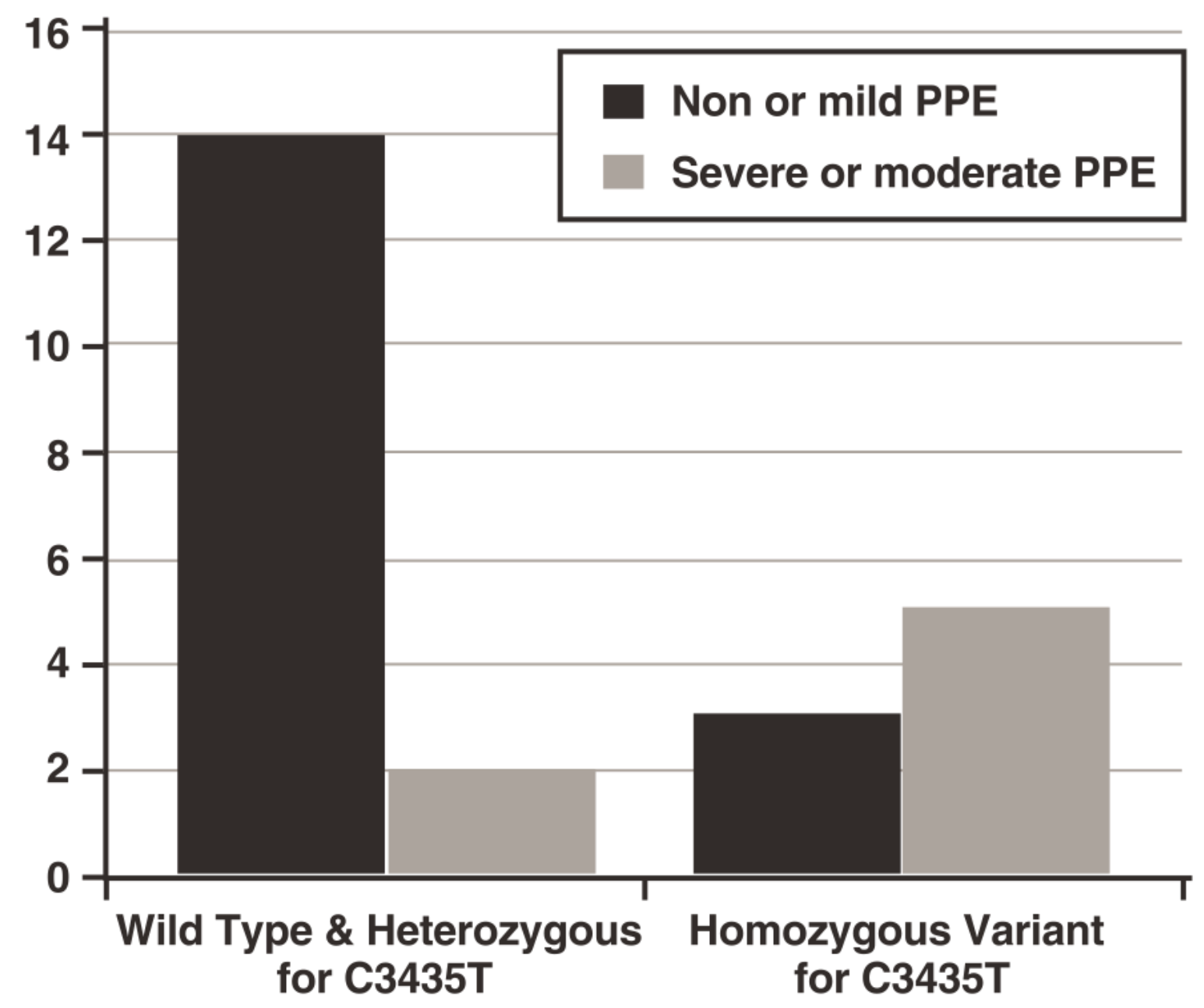


Figure 4.
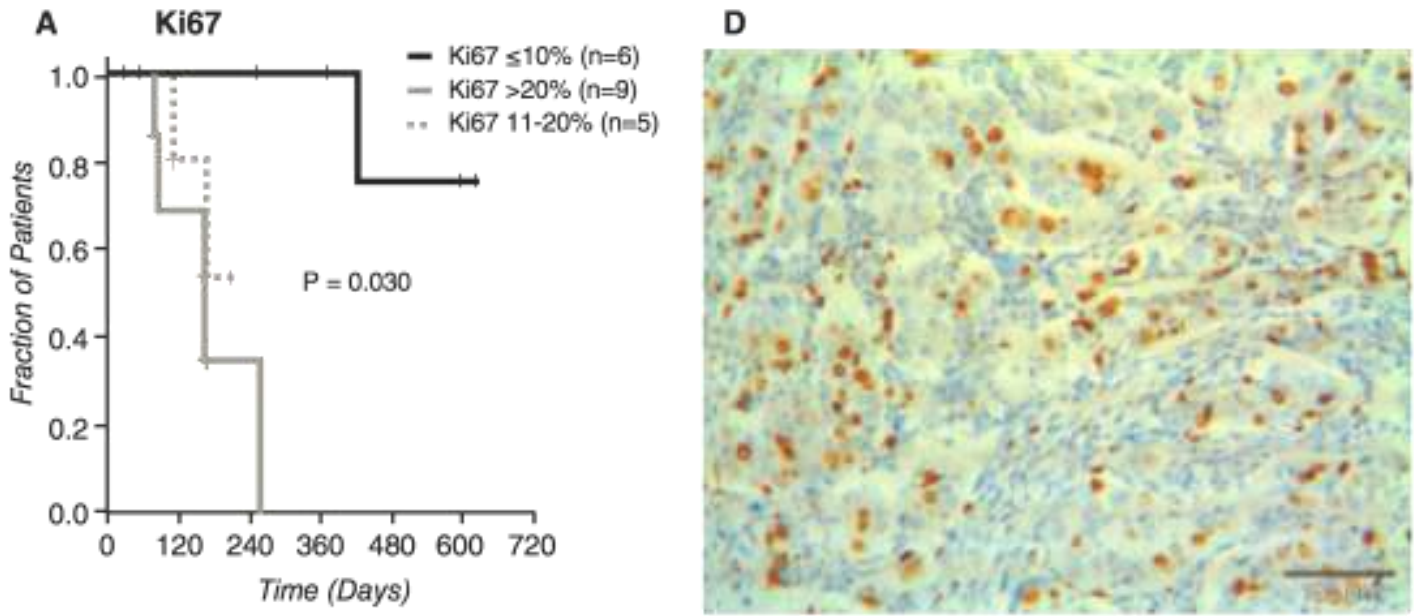

B TOPOlla : Ki67 ratio

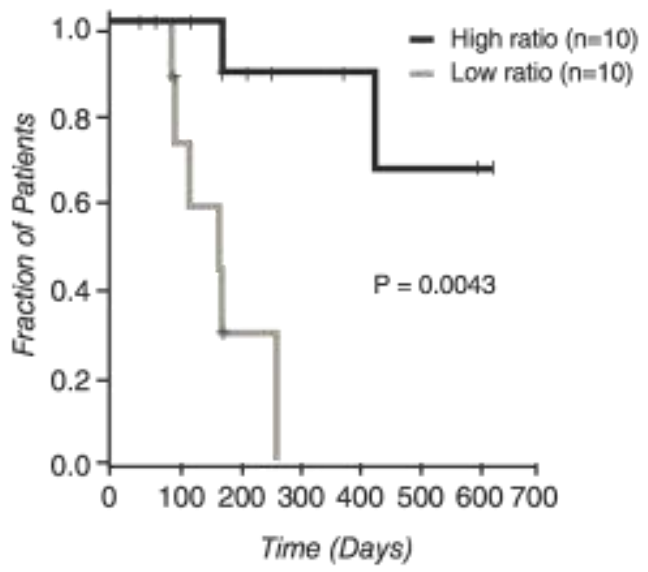

E

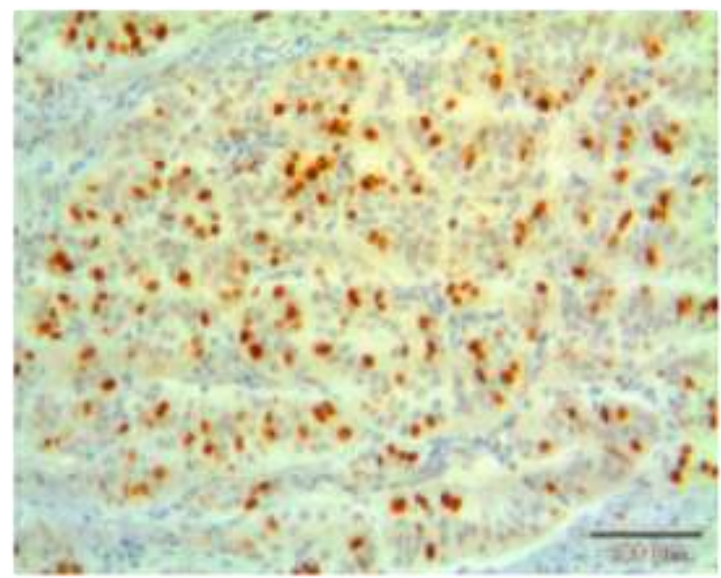

\section{MRN Score}

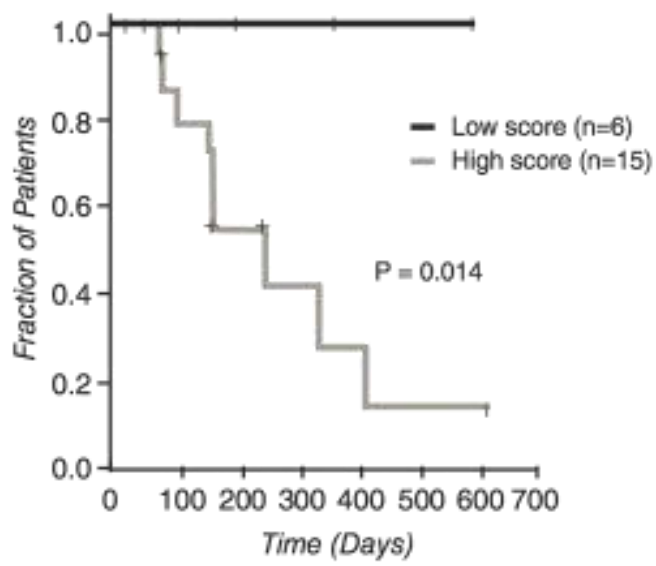

F

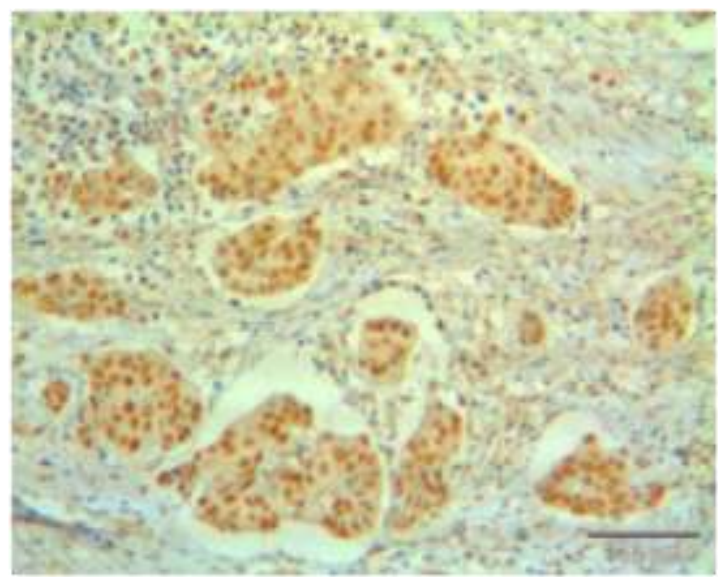




\section{Figure Captions}

Fig. 1 A) Effects of ABCB1 genotypes G2677T and C3435T on time to treatment failure. Patients homozygous (T/T) for ABCB1 SNP G2677T had a significantly shorter TTF when compared with patients having wild type $(G / G)$ and heterozygous genotypes $(G / T)$ $P=0.03$.

B) The pyrograms for the sequencing of the SNPs G2677T and C3435T. The G2677T SNP is sequenced on the reverse strand and the upper part shows the pyrograms for $2677 \mathrm{G} / \mathrm{G}, 2677 \mathrm{G} / \mathrm{T}$ and $2677 \mathrm{~T} / \mathrm{T}$. C3435T is sequenced on the forward strand and the lower part shows the pyrograms for 3435C/C, 3435C/T and 3435T/T.

Fig. 2 Effects of ABCB1 genotypes G2677T and C3435T on time to progression. Patients homozygous (T/T) for ABCB1 SNP G2677T had a significantly shorter TTP when compared to patients having wild type $(G / G)$ and heterozygous genotypes (G/T) $P<0.001$.

Fig. 3 Correlations between ABCB1 genotype and toxicity. Patients homozygous variant (T/T) for $A B C B 1$ SNP C3435T were more susceptible to palmar-plantarerythrodysesthesia compared to wild type $(\mathrm{C} / \mathrm{C})$ and heterozygous $(\mathrm{C} / \mathrm{T})$ patients $P=0.02$.

Fig. 4 Time to progression in relation to Ki67 (A), TOPOlla:Ki67 ratio (B), and MRN score (C) . Ki67 could be scored for 20 of the patients. TOPOIla and MRN score were 
possible to assess for 21 patients. Tumor tissue from one of the patients immunostained for Ki67, scored as high (D), TOPOlla, strong intensity and high TOPOlla:Ki67 ratio (E), and MRE11, high score, representing one of the proteins in the MRN complex (F).

Footnote: abbreviations:

AE: adverse event

CR: complete response

CT: computerized Tomography

LVEF: left ventricular ejection fraction

MBC: metastatic breast cancer

MRN complex: MRE11/RAD50/NSB1

OR: overall response

OS: overall survival

PD: progressive disease

PLD: pegylated liposomal doxorubicin

PPE: palmar-plantar-erythrodysestesia

PR: partial response

PS: performance status

SAE: serious adverse event

SD: stable disease

SNP: single nucleotide polymorphism 
TOPOlla: topoisomerase Ila

TTF: time to treatment failure

TTP: time to progression

UCG: ultrasonic echocardiography 